\title{
Surgeon General's Armed Forces Feeding Project: body composition, physical fitness, nutritional knowledge and dietary intake during Royal Navy Initial Officer Training
}

\author{
J. L. Fallowfield, R. Cobley, S. K. Delves, A. Dziubak, T. Davey and A. J. Allsopp \\ Institute of Naval Medicine, Crescent Road, Alverstoke, Gosport, Hants PO12 2DL, UK
}

Royal Navy (RN) Officer Cadets (OCs) undergo 28 weeks of Initial Officer Training (IOT) at the Britannia Royal Naval College (BRNC), Dartmouth, UK. BRNC aims to train and educate OCs to meet the challenging physical and mental requirements of frontline service. The aim of this study was to evaluate the dietary intake and physiological responses of RN OCs completing the 28-week IOT syllabus.

RN OCs commencing training at BRNC were given an initial study brief, after which 105 OCs (89 male; 16 female) consented to participate. Anthropometric measures were made at the start, middle and end of training. Physical fitness was assessed at the same time points by the Multi-Stage Fitness Test, sit-ups and press-ups tests. Nutritional knowledge was evaluated by Parmenter and Wardle's General Nutritional Knowledge Questionnaire ${ }^{(1)}$. Dietary intake was recorded using a 4-d Food Diary based on the Food Record Card ${ }^{(2)}$.

Mean body mass, BMI and percentage body fat for the male and female OCs did not change during the 28-week training programme. Nevertheless, male OCs who successfully passed out of training had lower sum of skinfolds $(86.2 \pm 32.1 \mathrm{~mm} \mathrm{vs}$. $118.2 \pm 51.3 \mathrm{~mm}$; $P<0.05)$ and lower percentage body fat $(14.0 \pm 4.1 \%$ vs. $17.2 \pm 5.5 \% ; P<0.05)$ at the Start of Training than male OCs who failed IOT. The female data set was too small for comparison. Aerobic fitness of male and female OCs increased between the Start and Middle of Training ( $m 49.4$ (3.8) vs. 53.4 (3.8) ml.kg.min ${ }^{-1}$; $f 34.6$ (4.8) vs. $39.8(2.3)$ ml.kg.min $\left.{ }^{-1} ; P<0.05\right)$, but tended to have decreased by the End of Training ( $m 50.4$ (3.0) ml.kg.min ${ }^{-1} ; f 37.4(4.0) \mathrm{ml} . \mathrm{kg} . \mathrm{min}^{-1}$ ). Strength similarly increased over the first half of IOT $(P<0.05)$, but remained constant thereafter. Nutritional Knowledge did not change during IOT ( $m 62(7) \% ; f 64(8) \%)$, but these mean data were $10 \%$ higher than Nutritional Knowledge scores reported for Phase-1 RN recruits ${ }^{(3)}$. Total energy and macronutrient intakes (as percentage of total energy) are shown below.

\begin{tabular}{|c|c|c|c|c|c|c|c|c|c|c|}
\hline \multirow[b]{2}{*}{ Stage of Training } & & \multirow[b]{2}{*}{$n^{*}$} & \multicolumn{2}{|c|}{ Energy (MJ) } & \multicolumn{2}{|c|}{$\mathrm{CHO}(\%)$} & \multicolumn{2}{|c|}{ Fat $(\%)$} & \multicolumn{2}{|c|}{ Protein $(\%)$} \\
\hline & & & Mean & $\mathrm{SD}$ & Mean & $\mathrm{SD}$ & Mean & $\mathrm{SD}$ & Mean & $\mathrm{SD}$ \\
\hline \multirow[t]{2}{*}{$\overline{\text { Start }}$} & $m$ & 89 & 11.9 & 0.3 & 44 & 5 & 40 & 5 & 16 & 2 \\
\hline & $f$ & 16 & 10.5 & 1.9 & 48 & 5 & 37 & 5 & 14 & 2 \\
\hline \multirow[t]{2}{*}{ Middle } & $m$ & 46 & 11.2 & 2.8 & 47 & 6 & 38 & 5 & 17 & 2 \\
\hline & $f$ & 7 & 10.5 & 2.2 & 50 & 4 & 37 & 4 & 15 & 1 \\
\hline \multirow[t]{2}{*}{ End } & $m$ & 29 & 11.3 & 6.8 & 43 & 9 & 35 & 6 & 17 & 4 \\
\hline & $f$ & 5 & 9.6 & 0.1 & 45 & 8 & 32 & 4 & 15 & 2 \\
\hline
\end{tabular}

* Sample size decreased as OCs voluntary withdrew from IOT, or failed a criterion assessment.

The total energy and micronutrient intake of OCs was generally consistent with current military guidelines ${ }^{(4)}$, but the proportion of carbohydrate was less than optimal for recovering from daily physical training ${ }^{(5)}$. 'Snacking' was identified as a widespread eating behaviour amongst OCs, and a potential source of poor eating habits. Future research will explore the eating behaviour of RN OCs to better inform specific nutritional education programmes.

The authors would like to thank colleagues at the Britannia Royal Naval College, Dartmouth, UK, for their support and assistance.

1. Parmenter K \& Wardle J (1999) Development of a general nutrition knowledge questionnaire for adults. Eur J Clin Nutr 53, $298-308$.

2. Davey T, Delves SK, Allsopp AJ, Lanham-New SA, Kilminster S \& Fallowfield JL (2009) Validation of a Bespoke Food Record Card as a Method of Recording Dietary Intake in Royal Marine Recruits. Proc. Nutr. Soc.

3. Dziubak A, House C, Taylor R, Cobley R, Minnock E, Zioupos P, Davey T, Allsopp AJ \& Fallowfield JL (2011) Surgeon General's Armed Forces Feeding Project: An Evaluation of Physical Training Progression, Dietary Intake and Bone Health in Royal Navy Phase-I Recruits at HMS Raleigh. Institute of Naval Medicine Report No.: 2011.042.

4. Casey A (2008) Military Dietary Reference Values. QinetiQ Ltd., Farnborough, UK.

5. Fallowfield JL \& Williams C. (1993) Carbohydrate intake and recovery from prolonged exercise. Int J Sports Nutr 3, $150-164$. 